\title{
Water and Sanitation Facilities in selected schools in Ibadan, South-western Nigeria
}

\author{
${ }^{* 1}$ Rahmot Balogun-Adeleye, ${ }^{2}$ Abdulhakeem Abiola, and ${ }^{1}$ Toluwanimi Agbaje-Daniels \\ ${ }^{1}$ Department of Civil and Environmental Engineering, University of Lagos, Akoka, Nigeria \\ ${ }^{2}$ Department of Community Health and Primary Care, College of Medicine, University of Lagos, Nigeria
} \{rbalogun | oabiola\}@unilag.edu.ng | danielsatinuke@gmail.com

Received: 21-APR-2021; Reviewed: 22-MAY-2021; Accepted: 20-JUL-2021

http://dx.doi.org/10.46792/fuoyejet.v6i3.625

\begin{abstract}
Access to clean water and sanitation is a major requirement for all countries in achieving the Sustainable Development Goals (SDG). The main aim of the study was to investigate the state and condition of water and sanitary facilities in selected secondary schools within Oyo State, Ibadan, Nigeria. Data was collected through the use of structured questionnaires and interviews with the students and teachers. Physical observation was also done onsite to supplement data gathering. The results revealed that deep-tube wells and pit latrines were the most widely used water and sanitation facilities in the study area. $70 \%$ of the schools surveyed used traditional pit latrines while $73 \%$ of schools had deep-tube wells respectively. In addition, there were limited drinking water and hand washing facilities in all the schools investigated. This study therefore recommends that government should increase funding for the provision of water and sanitation facilities in all schools in this state; as these would ensure good and enabling environment for learning as well as reducing outbreak of infectious diseases.
\end{abstract}

Keywords- Facilities, Sanitation, Schools, SDG, Water.

\section{INTRODUCTION}

Chools are the most important places of learning after $\checkmark$ family. They are exciting learning environments for children and initiate change to societies (Jahan \& Roky, 2016). Education is no doubt important for children, but the status of their health and immediate environment should also be considered with utmost importance as these factors adversely affect their health and wellbeing (Seid \& Kumie, 2013). The provision of water and sanitation in schools has a positive impact on the health, learning and teaching environment of the children (Egbionla \& Amanambu, 2015). McMicheal (2019) reported that schools must have reliable water system, adequate and clean toilets, hand-washing facilities and sustainable hygiene promotion in order to ensure universal access to water, sanitation and hygiene (WASH) facilities in schools. Access to adequate WASH facilities in schools has also been linked to the achievement of Goal 6 of the Sustainable Development Goals (SDGs), which main focus is the availability and sustainable management of water and sanitation by 2030 (Antwi-Agyei et al., 2017).

A special report carried out by WHO and UNICEF in 2019 during the COVID-19 pandemic, revealed that 584 million children worldwide were without basic drinking water services and 367 million children did not have access to basic sanitation services in their schools. In terms of coverage, $69 \%$ of schools worldwide had basic drinking water source, $15 \%$ of schools had no drinking water service. It was also reported that many schools still lack access to piped water and made use of improved water sources such as rainwater, protected wells and boreholes.

${ }^{*}$ Corresponding Author

Section E- CIVIL ENGINEERING \& RELATED SCIENCES

Can be cited as:

Balogun-Adeleye R., Abiola A. and Agbaje-Daniels T. (2021): "Water and Sanitation Facilities in selected schools in Ibadan, South-western Nigeria", FUOYE Journal of Engineering and Technology (FUOYEJET), 6(3), 73-76. http://dx.doi.org/10.46792/fuoyejet.v6i3.625
Global coverage of access to basic sanitation services in schools was lower compared to safe drinking water (WHO/UNICEF, 2020). 63\% of schools worldwide had improved sanitation facilities and $19 \%$ of schools had no sanitation services. $63 \%$ of schools worldwide had improved sanitation facilities and $19 \%$ of schools had no sanitation services.

The provision of sanitation facilities in schools in 2019 improved by $40 \%$ compared to 2016 where 620 million children lacked access to sanitation services (WHO/UNICEF, 2018). Countries in Sub-Saharan Africa had less than $50 \%$ coverage for both water and sanitation services in schools. In Nigeria, $36 \%$ children in schools lack access to basic water services while $40 \%$ had no sanitation facilities (WHO/UNICEF, 2020). Lack of access to WASH facilities in Nigeria is one of the major factors leading to high morbidity and mortality rates especially among children under five. A report by UNICEF showed that at least 70,000 children under five years die of diarrhea annually as a result of contaminated drinking water and poor sanitary conditions (UNICEF, 2021). The aim of this study is therefore to assess the state and adequacy of water and sanitation facilities in selected schools in Ibadan, Oyo state, Nigeria.

\section{Materials ANd Methods}

\subsection{STUDY AREA}

Ibadan is the capital of Oyo State, Nigeria and has the highest population of people residing in the state. It is located in south- western Nigeria on longitude $7^{\circ} 15^{\prime}$ and $7^{\circ} 30^{\prime} \mathrm{N}$, latitude $3^{\circ} 50^{\prime}$ and $4^{\circ} 00^{\prime}$ E (Ayeni et al., 2020). According to NPC (2006), its population is estimated to be about $2,567,853$ and expected to be $3,464,000$ at $2.39 \%$ growth rate in 2019. Ibadan has a tropical wet and dry climate with a mean annual rainfall of $1500 \mathrm{~mm}$ and mean monthly temperature of $27{ }^{\circ} \mathrm{C}$ (Ayeni et al., 2020). The major sources of employment for the people of Ibadan are mostly retail trade, civil service, services and repair industries, educational services and farming. There are many educational and research institutions in the city of 
Ibadan, most common ones are University of Ibadan, Technology University, Lead City University, Kola Daisi University, Premier Polytechnic Ibadan, Institute of Agricultural and Research Technology, Moore plantation, School of Nursing, NISER, IITA, University College Hospital (UCH), among others.

\subsection{Study Population ANd SAmple Size}

The population considered in this study constitutes all public junior and secondary schools in Ibadan. According to the list obtained from Oyo State Ministry of Education, Science and Technology, there were 209 Junior Secondary Schools and 174 Senior Secondary schools located in 11 Local Government Areas (LGAs) in Ibadan. Ibadan North, being the most populous has the highest number of schools (54) followed by Ibadan South West LGA. Ibadan North West and Lagelu Local Governments have the least number of schools (21) in their respective LGAs (Table 1). A total of fifty (50) secondary schools with average population not less than 500 students were randomly selected for the study. A cross sectional survey was done in August 2019. Data was obtained through structured questionnaires and observation checklists. The questionnaire consisted information about the population of students and staff, quantity and state of water supply and sanitary facilities in the selected schools. Data entry and analysis was done with Microsoft Excel software through the use of frequency tables and pie charts.

Table 1. Distribution of Junior and Senior Secondary Schools in Ibadan

\begin{tabular}{|c|c|c|c|}
\hline LGA & $\begin{array}{l}\text { No. of } \\
\text { Junior } \\
\text { Schools } \\
\end{array}$ & $\begin{array}{c}\text { No. of } \\
\text { Senior } \\
\text { Schools } \\
\end{array}$ & $\begin{array}{l}\text { Total No. } \\
\text { of Schools }\end{array}$ \\
\hline Akinyele & 29 & 15 & 44 \\
\hline Egbeda & 18 & 19 & 37 \\
\hline $\begin{array}{l}\text { Ibadan } \\
\text { North }\end{array}$ & 29 & 25 & 54 \\
\hline $\begin{array}{c}\text { Ibadan } \\
\text { North East }\end{array}$ & 20 & 14 & 34 \\
\hline $\begin{array}{c}\text { Ibadan } \\
\text { North West }\end{array}$ & 11 & 10 & 21 \\
\hline $\begin{array}{c}\text { Ibadan South } \\
\text { East }\end{array}$ & 19 & 17 & 36 \\
\hline $\begin{array}{c}\text { Ibadan South } \\
\text { West }\end{array}$ & 26 & 22 & 48 \\
\hline Ido & 13 & 9 & 22 \\
\hline Lagelu & 13 & 8 & 21 \\
\hline Oluyole & 20 & 18 & 38 \\
\hline Ona Ara & 11 & 17 & 28 \\
\hline Total & 209 & 174 & 383 \\
\hline
\end{tabular}

\section{Results and Discussion 3.1 STUDENTS' POPULATION}

The distribution of pupils in the selected schools showed that the total population of pupils was 38,473. Of the 38,473 pupils, $55 \%$ were girls and $45 \%$ were boys. Table 2 revealed that Ibadan South West had the highest number of students' enrollment with 8,807 pupils.
Table 2. Population of Pupils in Selected Schools

\begin{tabular}{|c|c|c|c|c|}
\hline \multirow[t]{2}{*}{ LGA } & \multirow{2}{*}{$\begin{array}{c}\text { No. of } \\
\text { School } \\
\text { s }\end{array}$} & \multicolumn{2}{|c|}{$\begin{array}{c}\text { Total No. of } \\
\text { Pupils }\end{array}$} & \multirow[t]{2}{*}{ Total } \\
\hline & & Girls & Boys & \\
\hline Akinyele & 2 & 620 & 681 & 1,301 \\
\hline Egbeda & 7 & 2,331 & 2,188 & 4,519 \\
\hline $\begin{array}{l}\text { Ibadan } \\
\text { North }\end{array}$ & 11 & 3,407 & 3,790 & 7,197 \\
\hline $\begin{array}{l}\text { Ibadan } \\
\text { North East } \\
\text { Ibadan }\end{array}$ & 6 & 1,511 & 1,481 & 2,992 \\
\hline $\begin{array}{l}\text { North } \\
\text { West }\end{array}$ & 4 & 1,051 & 1,023 & 2,074 \\
\hline $\begin{array}{l}\text { Ibadan } \\
\text { South East }\end{array}$ & 7 & 4,506 & 3,528 & 8,034 \\
\hline $\begin{array}{c}\text { Ibadan } \\
\text { South West }\end{array}$ & 8 & 6,091 & 2,716 & 8,807 \\
\hline Ido & 1 & 338 & 373 & 711 \\
\hline Lagelu & 3 & 989 & 1,216 & 2,205 \\
\hline Oluyole & 1 & 357 & 357 & 714 \\
\hline Total & 50 & 21,201 & 17,272 & 38,473 \\
\hline
\end{tabular}

\subsection{TOILET FACILITIES}

The study revealed that there was a total of 255 different types of toilet facilities in the selected schools. All the selected schools surveyed had at least one toilet facility in the school premises. $70 \%$ (178) of the toilet facilities were traditional pit latrines, followed by ventilated improved pit latrine (VIP) at 22\% (57) and $8 \%$ (20) flush toilets respectively (Figure 1). Previous studies have also shown that majority of toilet facilities in most public secondary schools were traditional pit latrines (Agbo et al., 2012; Seid \& Kumie 2013; Egbinola \& Amanambu 2015; Appiah-Brempong et al. 2018).

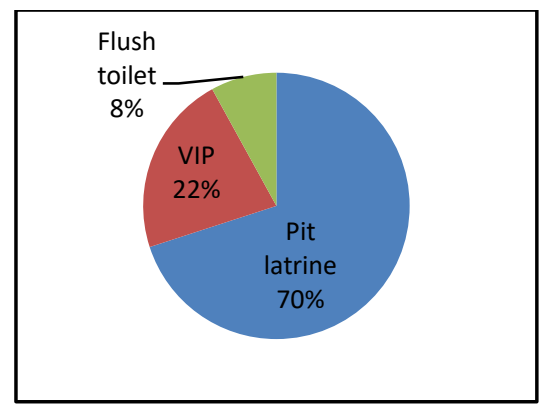

Fig. 1: Toilet Facilities in Surveyed Schools

All the schools had separate section for males and females and equal number of toilets was provided for both. According to UNICEF (2019) sufficient toilets must be available in schools at one toilet cubicle per 25 girls and one toilet cubicle per 50 boys. In this study, there was disparity in access to toilets by male and female students; none of the schools met the student-to-toilet ratios for males and females. The status of toilet facilities is also similar with findings in other developing countries. A review of sanitation facilities in 2270 rural schools in some parts of Africa by Morgan et al. (2017) revealed that fewer than 23\% of these schools met the recommended student-to-latrine ratios. In terms of functionality, majority of the sanitary facilities in the selected schools were not properly 
maintained. Some of the pit latrines were dilapidated (Figure 2a) and abandoned (Figure 2b), while those functioning lack well-fitting doors and roofs. The flush toilets were majorly for staff in the schools. Lack of adequate sanitary facilities in schools was reported by Wambugu \& Kyalo, (2014), for been responsible for poor performance and increased absenteeism of girls in primary schools in Kenya.

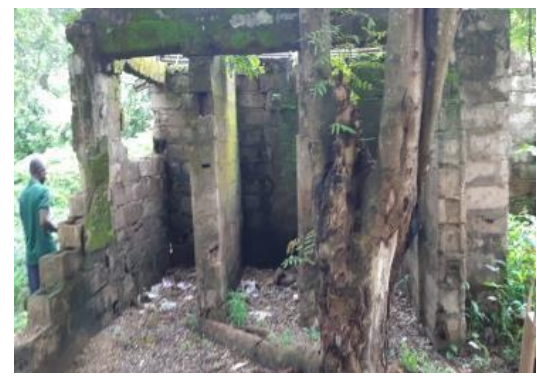

(a)

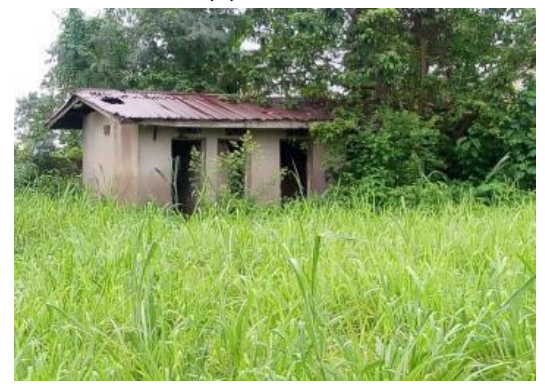

(b)

Fig. 2: (a) Dilapidated and (b) Abandoned Toilet, Facilities in Surveyed Schools

\subsection{URINALS}

There were no appropriate and conducive urinals in all the surveyed schools. Observations at the surveyed schools and consultations with the school officials revealed that the students used nearby bushes whenever they wanted to urinate. The female students were also not exempted from this act. Available toilets or secluded areas as well as sheds were made to serve as urinals and they did not provide the desired privacy as seen in Figures 3 (a and $b$ ).

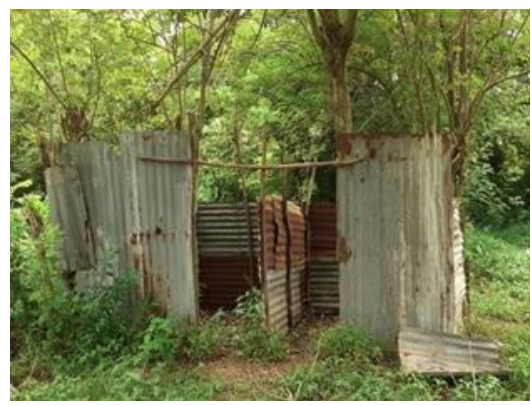

(a)

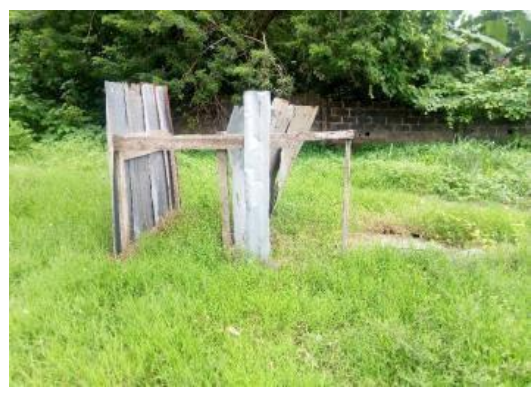

(b)

\subsection{WATER SUPPLY FACILITIES}

The study observed that $95 \%$ of the surveyed schools had functional water supply facilities in the school premises (Figure 4). The most common source was the deep tubewell $(73 \%)$, followed by borehole $(22 \%)$. This is similar to findings in Bangladesh (Jahan \& Roky, 2016) where tube wells were also the major source of drinking water in schools.

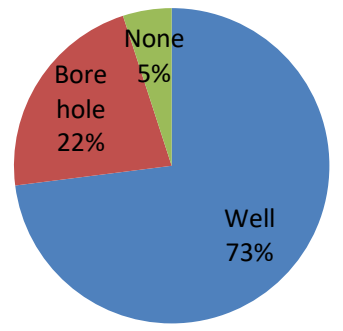

Fig. 4: Source of Water Supply

Site visit showed that some schools had both wells and boreholes as their source of water supply. The wells were used whenever there was lack of electricity to pump water for the students. It was pathetic to note that none of the schools had piped-borne water from the public pipes and about $5 \%$ of the surveyed schools had no source of water supply. The schools without source of water supply depend on the community and streams in the vicinity.

Although most of the schools had functional water facilities, there were limited taps for drinking and hand washing after toilet usage. The staff and students preferred to buy sachet water to drinking from the school source of water. The staff and students are not totally free from waterborne diseases through the consumption of sachet water. The safety of sachet water is entirely dependent on the water source, treatment, packaging and storage (Olaniyan et al. 2016). Increasing rates of infectious and gastrointestinal diseases have also been discovered in schools where water and sanitation facilities are inadequate (Morgan et al., 2017).

\subsection{Solid WASte DisPosal}

Open dumping of waste was the most prominent method of waste disposal in the selected secondary schools visited. Some portions of the school were designated for waste disposal and waste were burnt accordingly (Figures $5 a$ and $b$ ). Dumping of wastes in the school premises is a way of endangering the students' lives through the emergence of diseases that may infect the students. This is in agreement with Ikemika, (2015). Boreholes situated close to these dumpsites can also be contaminated due to the leachate emanating from the dumpsites as supported by Nwosu et al. (2021).

Fig. 3: State of two different Urinals in surveyed schools 


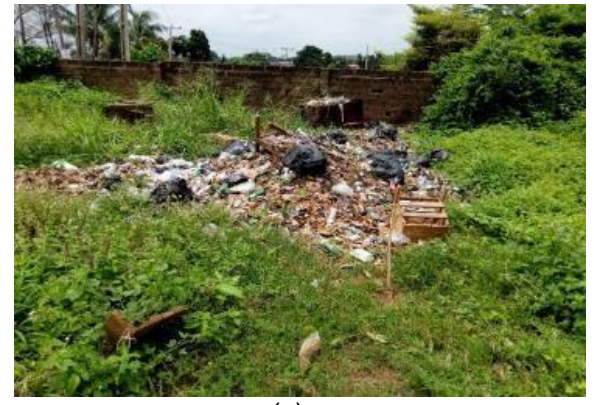

(a)

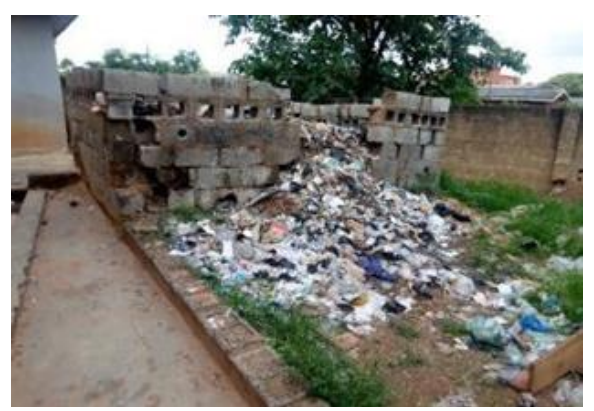

(b)

Fig. 5: Open Dumping of two different wastes in Surveyed Schools

\section{Conclusion}

It is evident from this study that there is deficit of water and sanitation facilities in the secondary schools investigated. None of the schools were connected to the pipe-borne public water supply facilities and this resulted in limited taps for drinking and handwashing after toilet usage. Majority of the toilet facilities and urinals provided in the schools were dilapidated and abandoned, this could lead to increased open defecation and absenteeism of pupils from schools. This study recommends that the State Government should make drastic efforts in increasing monetary allocations for the provision of WASH facilities in schools in Oyo State, Nigeria.

\section{REFERENCES}

Agbo, H.A., Envuladu, E.A., Adah, U.G. \& Zoakah, A.I. (2012). An assessment of toilet facilities in secondary schools in Jos North Local Government Area of Plateau State. Greener Journal of Educational Research, 2(4), 91-94

Akoteyon, I.S. (2019). Inequalities in Access to Water and Sanitation in Rural Settlements in Parts of Southwest Nigeria. Ghana Journal of Geography, 11(2), 158-184

Antwi-Agyei, P., Mwakitalima, A., Seleman, A., Tenu, F., Kuiwite, T., Kiberiti, S. \& Roma, E. (2017). Water, sanitation and hygiene (WASH) in schools: results from a process evaluation of the National Sanitation Campaign in Tanzania. Journal of Water, Sanitation and Hygiene for Development, 7(1), 140- 150

Appiah-Brempong, E., Harris, M.J., Newton, S. \& Gulis, G. (2018). Examining school-based hygiene facilities: a quantitative assessment in a Ghanaian municipality. BMC Public Health, 18, 581

Ayeni, O.D., Adediran, A., Ofordu, C.S., Mba, N.C. \& AmooOnindundu, O.N. (2020). Analysing the characteristic-sequence of rainfall amounts in Ibadan, Nigeria. Journal of Meteorology and Climate Science, 18(1), 89-98

Egbinola, C.D. \& Amanambu, A.C. (2015). Water supply, sanitation and hygiene education in secondary schools in Ibadan, Nigeria. Bulletin of Geography. Socio-economic Series, 29, 31-46

Jahan, S. \& Roky, M.R.H. (2016). A comparative study of the sanitation practices between urban and sub-urban school children in Jessore District, Bangladesh. International Research Journal of Public and Environmental Health, 3(3), 47-54

Ikemike, D.O. (2015). Effective Solid Waste Management: A Panacea to Disease Prevention and Healthy Environment in Bayelsa State, Nigeria. International Journal of Academic Research in Education and Review, 3(3), 65-75.

McMicheal, C. (2019). Water, Sanitation and Hygiene (WASH) in Schools in Low-Income Countries: A Review of Evidence of Impact. International Journal of Environmental Research and Public Health, 16, 359

Morgan, C., Bowling, M., Bartram, J. \& Kayser, G. (2017). Water, sanitation, and hygiene in schools: Status and implications of low coverage in Ethiopia, Kenya, Mozambique, Rwanda, Uganda, and Zambia. International Journal of Hygiene and Environmental Health, 220, 950-959

Nwosu, G.E., Badejo,A.A.,Adekunle, A.A. \& Adeosun, O.J. (2021). Assessment of spatio-temporal levels of pollution parameters due to dumpsite leachate in Lagos, Southwest Nigeria. FUOYE Journal of Engineering and Technology, 6(1), 113-116

Olaniyan, S.O., Adeyemi, A.S. \& Adeleke, W.O. (2016). Determination of shelf-life of selected sachet water in Ogbomoso, Oyo state, Nigeria. FUOYE Journal of Engineering and Technology, 1(1), 127-131

Seid, H. \& Kumie, A. (2013). The status of school sanitation facilities in some selected primary and secondary schools in Dessie City Administration, South Wello Zone, Amhara Region. Ethiopia Journal Health and Development, 27(1), 80-84

Sibiya, J. E. \& Gumbo, J.R. (2013). Knowledge, Attitude and Practices (KAP) Survey on Water, Sanitation and Hygiene in Selected Schools in Vhembe District, Limpopo, South Africa. International Journal of Environmental Research and Public Health, 10, 2282-2295.

UNICEF, (2021). Water, Sanitation and Hygiene. https://www.unicef.org/nigeria/press-releases/usaid-supportsunicef-improve-water-sanitation-and-hygiene-services-northwest.Accessed June 18, 2021

Wambugu, P.M. \& Kyalo, P. (2014). The effect of the adequacy of sanitary facilities on girls' participation in primary schools of Nakuru Municipality, Nakuru County, Kenya. International Journal of Academic Research in Progressive Education and Development, 3(1), 150-156.

WHO/UNICEF (2018). Drinking water, sanitation and hygiene in schools: global baseline report 2018. https://www.who.int/water sanitation health/publications/jmp -wash-in schools/ Accessed May 15, 2020

WHO/UNICEF (2020). Progress on drinking water, sanitation and hygiene in schools: Special focus on COVID-19. Accessed at https://www.who.int/water sanitation health/publications/pro gress-on-wash-in-schools-focus-covid-19/en/. Accessed June 18, 2021 